monumentale del Priamàr. II.2. Palazzo della Logia -scavi 1969-1989-. I Materiali. Bordighera-Savona, 2001, pp. 257-289)

El sexto artículo es de José Francisco Rodríguez Gordillo y se trata de un estudio sobre materiales constructivos, en concreto del mortero. Intenta mostrar su importancia como elemento de conocimiento tecnológico y material para compatibilizar y seleccionar las materias primas con que producirlo. Además nos muestra una clasificación y explicación de las diferentes técnicas de investigación con que estudiar cualquier mortero, y que se puede obtener de cada una de ellas.

El último artículo realizado por María de la Oliva Rodríguez-Ariza es un estudio de los carbones vegetales, o Antracología, y las etapas a seguir para un estudio antracológico, tanto en lo relativo a la recogida de muestras como en lo referente a su conservación.
Como indica Antonio Malpica ${ }^{1}$ es indudable que para el entendimiento de todo proceso histórico exista la relación hombre y Naturaleza. Por ello, la Arqueometría es importante, para la documentación de unos datos que nos pueden dar la clave, por ejemplo, de unos patrones culturales como el comercio de unos determinados materiales o la imitación de un determinado tipo de industria, como la cerámica, o de modos constructivos. Patrones muchas veces que pueden llevar a error al utilizar, por comodidad, rapidez o economía la comparación morfológica o tipológica de forma exclusiva. Con el uso las técnicas arqueométricas podrían evitarse errores de interpretación que pueden llevar al traste cualquier investigación arqueológica.

José Manuel Crespo Valero

\title{
Navarro Espinach, Germán y Villanueva Morte, Concepción: Los mudéja- res de Teruel y Albarracín, Instituto de Estudios Turolenses, Zaragoza, 2003, 283 páginas, ISBN 84-96053-06-7
}

Tenemos un libro que evidencia como pocos la investigación documental realizada para la confección de un estudio. No solo no se esconde, sino que el trabajo de la obra es precisamente enseñarla y mostrar los resultados de forma clara. Desde luego, es una publicación que los que comienzan sus escarceos en el proceloso mundo de la investigación histórica documental deberían ver para observar cómo se debe comportar uno/a en estas tareas, con la prudencia, con el esmero, con el cuidado que un investigador que busque hacer ciencia y no folclore tiene que acometer.

El tema siempre resulta atractivo; es uno de los grupos objeto de nuestra sociedad, que indaga en el teatral espectáculo de la convivencia de las tres culturas. Pero hay regiones y comarcas completas en la geografía peninsular, y Aragón es una de ellas, donde no tienen que interpretar sino que la comunidad mudéjar y posteriormente morisca dejó una profunda huella en la memoria histórica. En ese sentido, es comparable a determinadas zonas del antiguo reino de Valencia y del de Murcia, sin que tengan nada que envidiar a la más que conocida Alpujarra granadinoalmeriense.

1 Malpica, A., «Arqueología de los paisajes medievales granadinos: medio físico y territorio en la costa de Granada», Arqueología y territorio Medieval, 2, 1995, pp. 25-62. 
Centrado en el Sur del reino aragonés, los autores anuncian desde el comienzo del estudio sus intenciones: el prólogo lo utilizan para explicar, literalmente, el libro y su contenido; digamos que reproducen el sumario en prosa. Tras un capítulo de revisión historiográfica y bibliográfica, pasan a un apartado segundo donde especifican claramente su proyecto de trabajo y sabemos de sus planteamientos. Es como si la introducción hubiera asaltado el cuerpo mismo de la obra; qué pretenden y cómo lo han hecho, qué han estado analizando, en definitiva, la exposición de su tarea investigadora. Asumen una postura muy interesante y es la de plantear que no es lógico estudiar estas comunidades de forma aislada, cuando en realidad no lo estaban. El concepto de marginación grupal que utilizamos en realidad es ficticio, y así lo exponen; en lugar distinto y distante, pero paralelo, la zona oriental del reino de Granada tras la conquista, vemos que es el diseño de partida para analizar los enclaves del Almanzora, mudéjares, con respecto a Vera o Mojácar, núcleos de repoblación castellana. En este sentido, y con las posibilidades documentales que poseen y utilizan (que una cosa no implica siempre la otra), la versatilidad de la prosopografía está fuera de toda duda.

Mudéjares aragoneses (pp. 53-62) y mudéjares valencianos (pp. 67-75), con sendas tablas cuantitativas de los dos grupos (pp. 75-76), son recogidos como los componentes de la comunidad islámica en la zona estudiada. Interesa esta distinción por el presupuesto aludido con anterioridad, donde el aislamiento mudéjar solo responde a propuestas ya desfasadas.

En el cuarto capítulo, el del censo prosopográfico, aparte de especificar y advertir de los posibles deslices por la complejidad de la investigación, se in- cluye un versátil listado de abreviaturas (pp. 78-79) que aliviarán la enumeración expositiva de los individuos (pp. 80-154). El quinto apartado recoge las trayectorias familiares. En él se centran en el estudio antroponímico, concienzudo y detallista, con base en otro previo de Laliena Corbera (que utilizan como estudio general); un análisis de los oficios, como el de los trajineros, concretados en los Vera, los Caver, los Ferrero (o Ferrara), Liria, Izquierdo y Rubio (pp. 165-166), de las migraciones (básicamente las de corto radio), y el del comportamiento familiar y social, con especial atencion a las cuestiones judiciales por causas criminales, completa este capítulo.

El sexto recoge un examen sociotopográfico y de cultura material, indicando la localización y la forma de las morerías, con la peculiaridad de la turolense, que no era cerrada. Insertan los autores aquí los inventarios de bienes que se podían hallar en las casas de estos recintos, u ocupadas por mudéjares, con un listado final, breve, de términos muy útil para otros estudiosos, incluidos los de Historia de la Lengua (pp. 198-200). La siguiente sección está centrada en las tareas agropecuarias y artesanas a las que la mayor parte de la comunidad mudéjar se dedicaba. La importancia del grupo en esas actividades la plantean sin dejar lugar a dudas para la vida en el sector estudiado; particularmente me interesó mucho la conexión comercial con lugares a priori tan lejanos como lo era el Sur de la Corona catalano-aragonesa, en concreto con la Gobernación oriolana.

El capítulo octavo, centrado en el comercio, endeudamiento y conversión del grupo, va a poner el colofón al estudio. La dedicación a las labores comerciales era interesante, aunque en menor grado que 
los judíos aragoneses (p. 223), incluido el sector servicios como médicos, físicos y mercaderes; aquí podemos observar el control y la dedicación que a la aduana de Barracas le ha dedicado la Dra. Villanueva, aparecida en otras publicaciones ${ }^{1}$, y que se plasma en este estudio en un registro de los mudéjares en el citado paso comercial castellonense desde 1444 a 1447 (pp. 235-250). También aluden los autores de forma breve, aunque muy exhaustiva, a los niveles de endeudamiento de las diversas comunidades, y mucho más específico resulta el proceso de conversión («otra circunstancia que singularizó todavía más la historia de la comunidad mudéjar del sur de Aragón»). Fue muy temprana, paralela a la realizada por los de la Corona castellana, y que contrasta con los del conjunto aragonés y valenciano, y con el caso concreto de Gea, donde sí se convirtieron en 1526 por razón de parapeto señorial. El resto se convertía por propia conveniencia, si bien también recogen la marcha de quien no quiso el bautizo.

El punto y final a la obra la pone un registro de la documentación consultada y analizada, junto a una muy buena bibliografía seleccionada sobre el tema, lo que

1 Como las aportaciones realizadas a los diversos simposios de jóvenes medievalistas: «Aproximación a la sociedad mudéjar del sur de Aragón y norte del reino de Valencia en el trasiego mercantil de la Baja Edad Media» (Lorca 2002. Actas I Simposio de Jóvenes Medievalistas, Murcia, Universidad, 2003, pp. 235-260), «El tráfico de pescado en la frontera entre Aragón y Valencia: su intercambio comercial en la aduana de Barracas a mediados del siglo XV» (Lorca 2004. Actas II Simposio Internacional de Jóvenes Medievalistas, Murcia, Universidad, 2006, pp. 251-270) y «El sistema de alojamiento y hospedaje de los viajeros bajomedievales en el trayecto de Valencia a Zaragoza» (Lorca 2006. Actas III Simposio Internacional de Jóvenes Medievalistas, Murcia, Universidad, en prensa). contribuye a refrendar la fórmula ortodoxa de la investigación bien hecha y mostrada y que no hace otra cosa que reafirmar lo que vengo indicando desde el principio de la reseña.

Podemos por tanto, darnos por satisfechos como profesionales de la investigación histórica por contar entre la bibliografía, siempre extensa de este tema, con un nuevo título que contribuye a sostener la realidad de que el interés por las comunidades islámicas en la Península Ibérica, lejos de mantenerse, no deja de crecer. Y, por supuesto, congratularnos de que los autores hayan podido y sabido ofrecernos una tarea honesta y rigurosa de las formas de hacer Historia, algo de lo que, con los tiempos de avalancha que corren, es más que agradecer tanto al Dr. Navarro como a la Dra. Villanueva. Me refiero, claro, a la dignidad del oficio de historiador, donde no debe de importar meterse de vez en cuando al lodazal de las primeras investigaciones analíticas, concienzudas y con la pesada losa de la duda permanente acerca de la rectitud en la investigación: el manejo de los datos documentales, la exposición clara y contundente de los resultados y un estilo correcto de escritura son valores que nunca debemos dejar de recordar.

Juan Francisco Jiménez Alcázar 